\title{
QUEM TEM MEDO DOS ESTUDOS CULTURAIS?
}

\author{
Rosângela Fachel de Medeiros \\ Rosângela Fachel de Medeiros é doutoranda em Literatura Comparada pela Universidade Federal do Rio Grande do Sul.
}

\begin{abstract}
RESUMO: The main objective of this article is to discuss the viewpoints of some of the most known Brazilian comparative theorists regarding the difficult relation between Cultural Studies and Comparative Literature in Brazil, in an attempt to develop a brief review of the different ways of considering Cultural Studies and their presence in the comparative action.
\end{abstract}

PALAVRAS-CHAVE: Estudos Culturais. Literatura Comparada.

As discussões acerca da relação entre Literatura Comparada e Estudos Culturais têm se revelado um terreno movediço, com fronteiras nebulosas, de difíceis conclusões (mas quem deseja conclusões?). Cada vez mais parece que a questão está em manter, com unhas e dentes, um espaço "ilusório" de domínio acadêmico teórico-crítico. E talvez, mais do que se queira acreditar, tudo não passe da exteriorização de uma sensação de insegurança e de medo? Medo dos comparatistas de serem suplantados no interior dos Estudos Culturais, e medo dos críticos culturais de serem vistos apenas como mais uma vertente da Literatura Comparada. Mas afinal, entre nós comparatistas: Quem tem medo dos Estudos Culturais?

Em nosso universo comparatista os Estudos Culturais surgem como parte de uma tendência interdisciplinar inerente à disciplina (principalmente na tradição comparatista norte-americana) que, apesar de estar atualmente consolidada no interior da ação comparatista, ainda é vítima de certo torcer de nariz. Mas, se o fato de a Literatura Comparada não apresentar demarcado, com exatidão e objetividade, o seu campo específico de atuação, é visto por muitos como um problema a ser resolvido, cabe aqui ressaltar que é justamente esta possibilidade de trânsito entre disciplinas, linguagens e áreas do saber o que propicia ao ato comparatista a condição de arriscar-se por terrenos até então desconhecidos ou desconsiderados, revelando situações que de outra forma não seriam contempladas. A própria condição contemporânea e suas inquietações (questionamentos acerca do tempo e do espaço, das múltiplas identidades culturais, das noções de cânone e contra-cânone, bem como da noção de nação e das desta decorrentes, como: identidade, fronteira, limite e trânsito, que, por sua vez, se estende ao plano teórico-crítico, colocando em xeque as especificidades disciplinares), clamando por uma mobilidade teórico-crítica que seja capaz de abarcá-las, e a Literatura Comparada revela-se então, graças a sua vocação pluridisciplinar, como um dos melhores caminhos a ser adotado.

Este perfil da ação comparatista muito diferente de sua posição clássica é resultado das consideráveis transformações que a disciplina vem sofrendo desde meados da década de 70, em grande parte em decorrência da importância que adquirem correntes do pensamento como o Descontrustivismo, a Nova História e os Estudos Culturais e Pós-Coloniais. A disciplina passa então, nas palavras de Eduardo F. Coutinho, de um "discurso coeso e unânime, com forte propensão universalizante, para outro plural e descentrado, situado historicamente, e consciente das diferenças que identificam cada corpus literário envolvido no processo da comparação." "A literatura comparada que se mantivera até então fiel a dois alicerces inabaláveis: a pretensão universalizante e o discurso de apolitização; passa a assumir como uma de suas preocupações justamente a indagação destas posturas. Da mesma forma, conceitos tomados como referenciais seguros nos estudos comparatistas, como: nação, identidade, língua e literariedade passaram a ser questionados. Um dos resultados mais significativos destas transformações é o deslocamento do foco de ação da disciplina para regiões até então consideradas marginais, como: Ásia (China e Índia), África e América Latina. Contudo, existe um diferenciamento entre a atitude dos comparatistas nos centros hegemônicos (Europa Ocidental e América do Norte) e nas periferias (China, Índia, África e América Latina); no eixo Europeu Ocidental/América do Norte as pesquisas deslocaram-se para os grupos minoritários (étnicos e sexuais); já no eixo periférico ocorre o "desvio de olhar" que visa tratar as questões literárias a partir do próprio locus do pesquisador. A ação comparatista volta-se assim para questões contextualizadas, abrangendo uma rede complexa de relações culturais. Esta nova postura teórico-crítca resulta da desierarquização das produções culturais, em que a "literatura" deixa de ser vista como texto autônomo e independente.

Ao avançar por outras instâncias, a Literatura Comparada retira da "literatura" o caráter de ser o corpus específico e único de suas pesquisas, mas esta passa a compor através de suas relações e interferências com outras 
áreas do saber e da cultura a nova perspectiva destes estudos. Desta forma, a especificidade da ação comparatista, mantida através da restrição de campos e modos de atuação, foi substituída pela possibilidade de trânsito entre várias áreas (Não despropositadamente, o questionamento de noções como limites, fronteiras e geografias tem sido o tópico central e catalisador dos mais recentes eventos comparatistas. Através de tais propostas busca-se revisar paradigmas até então estanques, não apenas em um âmbito das questões de nacionalidade, mas igualmente em uma preocupação teórico-crítica e disciplinar). Eduardo Coutinho, em "Fronteiras imaginadas: o comparatismo e suas relações com a teoria, a crítica e a historiografia literárias", inicia seu texto tratando exatamente da intensa indagação acerca das fronteiras entre as disciplinas ou áreas do saber, gerada a partir do questionamento de noções como a de "identidade", "nação", "idioma" e "literariedade". Conforme Coutinho, o tráfego interdisciplinar tornouse uma das palavras de ordem dos estudos comparatistas, uma vez que "o confinamento das disciplinas dentro de seus próprios limites revelou-se absolutamente inadequado." ii Em decorrência disso, a idéia de limite entre as disciplinas só pode ser considerada enquanto "constructos móveis e provisórios" "iii. É neste processo de mobilidade que o comparatismo estabelece seu caráter interdisciplinar.

Contudo, a interdisciplinaridade, ou a transdisciplinaridade, foi por muito tempo, e ainda é para muitos, considerada uma ação de invasão de territórios a ser evitada, sendo acusada de utilizar um vocabulário teórico "miscigenado, de origem incerta", que seria o responsável por transformar o discurso crítico contemporâneo em um "jogo metafórico belo e vago." "iv Essa desconfiança por parte de muitos pesquisadores, alicerça-se no fato de verem na expansão dos estudos interdisciplinares uma ameaça à especificidade dos estudos literários em favor da ascendência dos Estudos Culturais, aqui reencontramos nosso vilão. Em decorrência disso, as discussões acerca do binômio "Literatura Comparada - Estudos Culturais" têm sido o centro de inúmeros encontros e simpósios comparatistas; dividindo opiniões entre os que são favoráveis e os que são contrários à interação entre o fazer comparatista e a crítica cultural.

No texto "Literatura comparada e estudos culturais", Eneida Leal Cunha trata a relação entre as áreas a partir de suas características "pós-disciplinares" (não sem, contudo, questionar a própria classificação), tomando como ponto chave para ambas "a insatisfação com as divisões disciplinares instituídas." A autora reconhece na Literatura Comparada (centrando-se na experiência brasileira, que para ela apresenta um perfil peculiar, diferindo tanto da experiência européia quanto da norte-americana) uma vastidão de interesses - diversidade de objetos de estudo; bem como uma persistência em ultrapassar fronteiras, reafirmando a insatisfação desta com os limites disciplinares e concluindo que muito do que vem sendo produzido em "nossa peculiar" Literatura Comparada "submete-se explicitamente ao rótulo de Estudos Culturais." "i

Wander Melo de Miranda, no texto "Projeções em debate", analisa a discussão acerca dos Estudos Culturais, cada vez mais presente no âmbito comparatista, uma vez que a abertura de outro viés de discussão redimensiona "os limites da interlocução comparatistas até a implosão de seus contornos disciplinares, colocando em xeque sua legitimidade institucional." "vii Para Miranda o ponto central das reações contrárias aos Estudos Culturais está no fato destes colocarem "em xeque a hegemonia de valores instituídos pela comunidade de letrados." "viii Uma vez que, tomando como seu objetivo central o estudo da formação de critérios de valor, os Estudos Culturais acirram o questionamento quantos a estes valores, utilizando para isso critérios tidos como extra-literários, e assim colocando em pauta a revisão do cânone, estabelecendo relações de proximidade com os estudos subalternos, os estudos das minorias, bem como os pós-coloniais.

Os entusiastas dos Estudos Culturais alegam a seu favor: o descentramento dos estudos comparatista, que passa a abarcar uma rede complexa de relações culturais (ocupando-se de questões de identidade cultural e nacional); o "desvio de olhar" através do qual o pesquisador passa a enfocar as questões literárias partindo de seu próprio locus de enunciação em oposição ao modelo eurocêntrico (Homi Bhabha, Edward Said); bem como o questionamento do cânone. Além disso, os Estudos Culturais colocam em questão não apenas os limites da disciplina comparatista, como também as noções de literatura e de "literariedade". Conforme Eneida Maria de Souza: "não se trata mais de se considerar a literatura na sua condição de obra esteticamente concebida, ou de valorizar critérios de literariedade, mas de interpretá-la como produto capaz de suscitar questões de ordem teórica ou de problematizar temas de interesse atual." ix

Tania Carvalhal, no texto "Literatura comparada e estudos culturais", não vê a relação entre as duas disciplinas como um embate, mas destaca o fato de, apesar de serem separadas por um fator essencial - a obrigatoriedade ou não da presença do literário em suas pesquisas (apesar de ainda manter a exigência da presença do fenômeno literário em seus estudos, a perspectiva predominante do literário em relação às demais manifestações artísticas vem gradativamente sendo abandonada em favor de um equilíbrio entre as manifestações no interior do processo comparatista), ambas as disciplinas convergem em alguns pontos. Uma vez que, na contemporaneidade, 
ávida por redefinir e questionar os limites e as fronteiras (teóricas, críticas e disciplinares), se deve sempre ter em mente que muitos dos alicerces que fundamentam estas duas formas de atuação crítica são conceitos que estão em constante redimensionamento e recodificação, por muitas vezes se imbricando e substituindo, fazendo com que não poucas vezes os estudos culturais e a literatura comparada compartilhem áreas de investigação e metodologias.

Contudo, Leyla Perrone-Moisés no texto "A crítica literária hoje", acusa os Estudos Culturais de minimizarem a literatura ao enfocá-la apenas como uma das formas da cultura, sendo seu estudo diluído no contexto da crítica cultural. Sem deixar de reconhecer a utilidade dos Estudos Culturais, Perrone-Moisés defende a manutenção de "um espaço específico para os estudos literários" e acusa o "culturalismo", com seu ecletismo privado de rigor na formação dos pesquisadores e na concepção de conceitos e juízos, de estar em ascensão em detrimento das disciplinas especializadas. O que Perrone-Moisés, assim como outros teóricos, postula é a existência de uma teoria rigorosa que impeça os estudos culturais e comparatistas de transformem-se no que Luiz Costa Lima definiu como "uma área do vale-tudo"x que segundo Heidrun Krieger Olinto transformaria a ação crítica em uma espécie de "armazém de secos e molhados"xi em que tudo é permitido.

Em seu texto "A teoria em crise", Eneida Maria de Souza, dialogando justamente com textos destes teóricos (Leyla Perrone-Moisés, Luiz Costa Lima e Heidrun Krieger Olinto), afirma que o que está em jogo no embate entre aqueles que defendem a existência de um rigor teórico-crítico e os entusiastas dos estudos culturais é o desejo em manter o controle epistemológico em relação ao objeto de estudo. Sendo que ao defenderem a manutenção de uma ação crítica rígida e sistemática, os primeiros se colocando contra o "culturalismo" que, para eles, invade a área literária; o que revela a "censura ao ecletismo e à falta de rigor na formulação de conceitos e de juízos próprios das tendências contemporâneas" "xii , denunciando sua "intolerância". Em outro texto, "Os livros de cabeceira da crítica", Eneida de Souza afirma:

Os grandes responsáveis pela pretensa confusão gerada pelos estudos culturais passam a ser, segundo alguns críticos, a multiplicidade de perspectivas teóricas, o pluralismo, o multiculturalismo, a democratização do lugar da literatura e seu valor como prática intersubjetiva, ao lado de um determinante maior, a contextualização. Se antes a teoria constituía o fator de universalização do enfoque crítico, pela abordagem de diferentes discursos sem distinção quanto ao contexto e à sua especificidade, o que atualmente se condena é a excessiva dose de contextualização. ${ }^{\text {xiii }}$

Pode-se concluir então que a inconformidade frente aos Estudos Culturais centra-se em duas questões principais: 1 - o fato destes não terem na literatura seu objeto primordial, podendo ocupar-se dela, além de outras manifestações culturais, ou excluí-la de suas pesquisas (o que muitos vêem como uma perda de identidade - diluição - do objeto de análise do comparatista); 2 - a sua presumida ausência de rigor teórico e de sistematização metodológica, que teria como responsáveis (culpados?): Gilles Deleuze e Gattari, Jacques Derrida e Michael Foucault, em decorrência de suas contribuições teóricas, como: as teorias da multiplicidade, da descontrução e da descontinuidade pós-estruturalista, e das noções advindas destas: disseminação, rizoma, suplemento, différance e literatura menor; referências fundamentais para a releitura de questões culturais. A acusação de falta de rigor teórico acaba resultando em outra acusação, a de destruir o conceito de origem, em um esquecimento dos percussores teóricos em favor de pensadores contemporâneos.

Mas deve-se destacar que o embate entre Literatura Comparada e Estudos Culturais não é uma via de mão única em que os críticos culturais são perseguidos pelos comparatistas, existindo igualmente por parte de alguns adeptos dos Estudos Culturais serias restrições à literatura comparada. Em uma oposição crítica que se baseia em velhas concepções, sem levar em consideração o fato de a ação comparatista ter sido inovadora, principalmente ao abordar materiais não-convencionais, como: correspondências, textos de viajantes, marginálias e mapas (tomandoos como "literatura de mediação"), em grau de igualdade aos outros materiais literários.

O debate entre Literatura Comparada e Estudos Culturais não deve, porém ser transformado em uma disputa partidária que coloque cada uma das posições contra a outra em um "binarismo excludente". A atual natureza plural das tendências críticas não permite mais a idéia de que uma teoria possa ser única e exclusiva, tornando-se perigosa a postura de acreditar que uma ou outra seja a detentora exclusiva da verdade. O mais produtivo agora parece ser a compreensão de que as fronteiras disciplinares, assim como os limites teóricos, já não se sustentam (ou melhor, são constructos móveis), valorizando cada vez mais a interdisciplinaridade, anteriormente tão atacada. Não há mais razão em tentar defender ou impor uma disciplina em detrimento de outra, o que seria, de certa forma, um pensamento redutor e ingênuo. Uma vez que a Literatura Comparada caracteriza-se (principalmente nas vertentes norte-americana e brasileira) por uma acentuada interdisciplinaridade, em um movimento de expansão e questionamento de seu objeto de estudo e de apropriação de fundamentos teóricos de diversos campos do saber; desta forma, seu diálogo como os Estudos Culturais parece estar consolidado e frutificando (mas nunca estanque ou 
acabado), apesar das diversas acusações e oposições. Questões como o "multiculturalismo"; bem como as noções de "transcultural", "hibridismo" e "entre-lugar", que nos são tão caras, não existiriam (nos trabalhos comparatistas), não fosse o entrecruzamento entre a Literatura Comparada e os Estudos Culturais.

No Brasil, a partir dos anos 70, são identificados vários trabalhos que, apesar de ainda não serem classificados como Estudos Culturais, já se encontram na fronteira entre literatura e cultura. Isto é demonstrado claramente por Silviano Santiago em seu texto: "Democratização no Brasil -- 1979-1981 (Cultura versus Arte)". Entre as muitas questões levantadas pelo crítico na abertura de seu texto uma parece resumir claramente a vereda cultural assumida pelo intelectual: "Quando é que arte brasileira deixa de ser literária e sociológica para ter uma dominante cultural e antropológica?" xiv Santiago apresenta então alguns textos nos quais a questão central é o debate das relações entre arte e cultura, cartografando o que poderia ser reconhecido como a emergência dos Estudos Culturais no Brasil. E em seu outro texto, "Crítica Cultural, Crítica Literária: desafios do fim do século", Santiago analisa a maneira como o fim do regime militar e a fragmentação das esquerdas em conjunto à afirmação da "indústria cultural" e da expansão dos mídias foram responsáveis por colocar por terra posições hieraquizantes e dicotômicas, entre: literário e não literário, erudito e popular; resultando em uma nova política de valores que privilegia o cultural ao literário, o ético-político ao estético, o cotidiano à tradição letrada, o "multicultural" ao canônico. Santiago evidencia em seus dois textos a forte tendência a uma crítica cultural existente no Brasil que, nem um pouco discretamente, é aprovada e instigada por ele. Entre os mais conhecidos críticos da área comparatista, parecem confluir com o olhar favorável de Santiago à integração entre Literatura Comparada e Estudos Culturais, Tania Franco Carvalhal, Wander Melo de Miranda e Eneida Maria de Souza, enquanto Leyla Perrone-Moisés, Luiz Costa Lima e Heidrun Krieger Olinto demonstram-se mais receosos à crítica cultural.

Eneida Leal Cunha reconhece no perfil "cultural", traçado por Santiago, das pesquisas brasileiras, um aporte para sua tese de que nossa pesquisa comparatista difere das demais, possuindo um caráter mais "cultural" (investigação de trânsitos, deslocamentos, confluências ou intervalos culturais, releitura das formações nacionais e a investigação dos diálogos entre nacionalidade, classe, gênero e etnicidade) que as outras. Contudo, ela afirma que isso ainda pouco para conceder as disciplinas (Literatura Comparada e Estudos Culturais) o "título" de pósdisciplinas. Para tanto, não bastaria apenas o ímpeto desconstrutor de disciplinas instituídas, mas seria necessário que se extrapolasse a própria questão disciplinar (abandonando o "diálogo entre pares"), e se buscasse estar a altura de "alianças eficazes" com outros grupos sociais e outros campos discursivos, até então eleitos, à distância. O que nos leva à pergunta que não quer calar: Quem (não) tem medo das pós-disciplinas?

Parece realmente que a questão das fronteiras disciplinares e da especificidade do objeto de estudos da Literatura Comparada (e dos Estudos Culturais) ainda é, e será, uma profícua inquietação. Nesse afã, nada melhor do que encerrar esse texto com um trecho do Relatório de Bernheiner que busca cartografar a seara ampla e movediça da ação comparatista:

O espaço de comparação hoje envolve comparações entre produções artísticas comumente estudadas por diferentes disciplinas; entre várias construções culturais daquelas disciplinas; entre tradições culturais ocidentais, tanto erudita quanto popular; e aquelas das culturas não ocidentais, entre produções pré e pós-contato cultural dos povos colonizados; entre construções de gênero definido como feminino e aqueles definidos como masculino, ou entre orientações sexuais definidas como normais e aquelas definidas como "gay", entre modos de significação racial e étnico; entre articulações hermenêuticas de significação e análises materiais de seus modos de produção e de circulação; e muito mais. Estes modos de contextualizar a literatura em amplos campos do discurso, cultura, ideologia, raça e gênero são tão diferentes dos antigos modelos de estudos literários, de acordo com autores, nações, períodos e gêneros, que o termo "literatura" pode não descrever mais adequadamente nosso objeto de estudo. ${ }^{\mathrm{xv}}$

\section{REFERÊNCIAS BIBLIOGRÁFICAS}

ANDRADE, Ana Luiza; ANTELO, Raul; BARROS, Maria Lucia Camargo (orgs). Leituras do Ciclo. Florianópolis: ABRALIC: Chapecó: Grifos, 1999, p 247-254.

ANTENELO, Raul (org). Declínio da arte: ascensão da cultura. Florianópolis: ABRALIC: Letras contemporâneas, 1998.

BITTENCOURT, Gilda Neves; MARQUES, Reinaldo (orgs). Limiares críticos: ensaios sobre literatura comparada. Belo Horizonte: Autêntica, 1998.

CARVALHAL, Tania Fraco; COUTINHO, Eduardo F (orgs.). Literatura comparada: textos fundadores. Rio de Janeiro: Rocco, 1994. 
. "Literatura comparada e teoria literária: intertextualidade e comunidades literárias". In: REVISTA TEMPO BRASILEIRO. Rio de Janeiro, No 114-115: 29/38, jul.-dez., 1993, p. 29-37.

. O próprio e o alheio: ensaios de literatura comparada. São Leopoldo: Editora Unisinos, 2003.

COUTINHO, Eduardo. "Literatura Comparada, literaturas nacionais e questionamento do cânone". REVISTA BRASILEIRA DE LITERATURA COMPARADA. N³, Rio de Janeiros: ABRALIC, 1996. p. 67-73.

. "Fronteiras imaginadas: o comparatismo e suas relações com a teoria, a crítica e a historiografia literárias". In: ANDRADE, Ana Luiza; ANTELO, Raul; BARROS, Maria Lucia Camargo (orgs). Leituras do Ciclo. Florianópolis: ABRALIC: Chapecó: Grifos, 1999, p 247-254.

CUNHA, Eneida Leal. "Literatura comparada e Estudos culturais". In: BITTENCOURT, Gilda Neves; MARQUES, Reinaldo (orgs). Limiares críticos: ensaios sobre literatura comparada. Belo Horizonte: Autêntica, 1998.

"Fronteiras Imaginadas: o Comparatismo e suas relações com a Teoria, a Crítica e a Historiografia

Literárias". In: ANDRADE, Ana Luiza et al. (orgs). Leituras do ciclo. Florianópolis: ABRALIC; Chapecó: Grifos, 1999. p. 247-253.

LIMA, Luiz Costa. "Comparatismo hoje”. In: Anais V Congresso ABRALIC. Rio de Janeiro, 1997, v. 1, p. 81-84.

MIRANDA. Wander Melo. "Projeções em debate". In: REVISTA BRASILEIRA DE LITERATURA COMPARADA. N4, Rio de Janeiros: ABRALIC, 1998. p. 11-17.

NITRINI, Sandra. Literatura comparada: história, teoria e crítica. São Paulo: Editora da Universidade de São Paulo, 1997.

OLINTO, Heidrur Krieger. "Interesses e paixões: histórias de literatura". In: OLINTO, Heidrur Krieger. (Org.) Histórias de literatura: as novas teorias alemãs. São Paulo: Ática, 1996.

PERRONE-MOISÉS, Leyla. "A crítica literária hoje”. In: Anais V Congresso Abralic. Rio de Janeiro, 1997, v.1, p. 85-89.

SANTIAGO, Silviano. "Democratização no Brasil -- 1979-1981 (Cultura versus Arte)". ANTENELO, Raul (org). Declínio da arte: ascensão da cultura. Florianópolis: ABRALIC: Letras contemporâneas, 1998.

SOUZA, Eneida Maria de. "Teoria em crise". In: REVISTA BRASILEIRA DE LITERATURA COMPARADA. No 4, 1998.

"Os livros de cabeceira da crítica". In: ANTENELO, Raul (org). Declínio da arte: ascensão da cultura. Florianópolis: ABRALIC: Letras contemporâneas, 1998.

Notas:

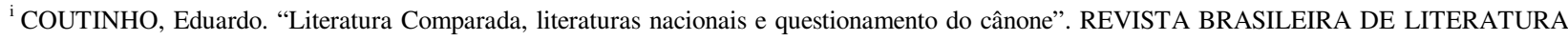
COMPARADA. N³, Rio de Janeiros: ABRALIC, 1996. p. 67.

${ }^{\text {ii }}$ COUTINHO, Eduardo. "Fronteiras imaginadas: o comparatismo e suas relações com a teoria, a crítica e a historiografia literárias". In: ANDRADE, Ana Luiza; ANTELO, Raul; BARROS, Maria Lucia Camargo (orgs). Leituras do Ciclo. Florianópolis: ABRALIC: Chapecó: Grifos, 1999 , p 247.

iii Idem, ibidem, p. 249.

${ }^{\text {iv }}$ OLINTO, Heidrun Krieger. "Interesses e paixões: histórias de literatura”. In: OLINTO, Heidrur Krieger. (Org.) Histórias de literatura: as novas teorias alemãs. São Paulo: Ática, 1996.

${ }^{v}$ CUNHA, Eneida Leal. "Literatura comparada e Estudos culturais". In: BITTENCOURT, Gilda Neves; MARQUES, Reinaldo (orgs). Limiares críticos: ensaios sobre literatura comparada. Belo Horizonte: Autêntica, 1998, p 67.

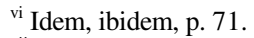

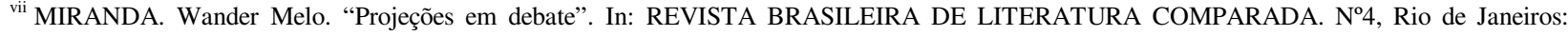
ABRALIC, 1998. p. 11.

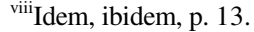

${ }^{\text {ix }}$ SOUZA, Eneida Maria. “A teoria em crise”. In: Revista Brasileira de Literatura Comparada, nº 4, 1998, p. 20.

${ }^{\mathrm{x}}$ LIMA, Luiz Costa. "Comparatismo hoje". In: Anais V Congresso ABRALIC. Rio de Janeiro, 1997, v. 1, p. 81-84.

${ }^{x i}$ OLINTO, op cit., p. 33.

xii SOUZA, Eneida Maria de. "A teoria em crise”. In: REVISTA BRASILEIRA DE LITERATURA COMPARADA. No . 4, 1998, p. 22.

xiii. Idem. "Os livros de cabeceira da crítica". In: ANTENELO, Raul (org). Declínio da arte: ascensão da cultura. Florianópolis: ABRALIC: Letras contemporâneas, p. 107.

${ }^{\text {xiv }}$ SANTIAGO, Silviano. "Democratização no Brasil -- 1979-1981 (Cultura versus Arte)", p. 11.

${ }^{\mathrm{xv}}$ Citado em: NITRINI, Sandra. Literatura comparada: história, teoria e crítica. São Paulo: Editora da Universidade de São Paulo, 1997, p. 120-1. 